\title{
Strategies for the Generation of Neuronal Diversity in the Developing Central Nervous System
}

\author{
Susan K. McConnell \\ Department of Biological Sciences, Stanford University, Stanford, California 94305
}

\begin{abstract}
During development, the neural tube produces a large diversity of neuronal phenotypes from a morphologically homogeneous pool of precursor cells. In recent years, the cellular and molecular mechanisms by which specific types of neurons are generated have been explored, in the hope of discovering features common to development throughout the nervous system. This article focuses on three strategies employed by the CNS to generate distinct classes of neuronal phenotypes during development: dorsal-ventral polarization in the spinal cord, segmentation in the hindbrain, and a lamination in the cerebral cortex. The mechanisms for neurogenesis exemplified by these three strategies range from a relatively rigid, cell lineage-dependent specification with a high degree of subservance to early patterns of gene expression, to inductions and cellcell interactions that determine cell fates more flexibly.

[Key words: neurogenesis, hindbrain, spinal cord, cerebral cortex, pattern formation, homeodomain, induction]
\end{abstract}

During embryonic development, the cells of the neural tube generate the enormous variety of neurons that will populate the central nervous system of the adult. Phenotypically diverse neurons must be produced, organized into functional units, and interconnected through the formation of specific axonal and synaptic contacts. These processes ultimately generate precisely wired neuronal circuits that underlie both simple and complex behaviors. Rather than employing a single, uniform strategy for the production of neuronal diversity, the neural tube appears to use a variety of cellular and molecular strategies to generate specific neuronal phenotypes. This article focuses on three such strategies within the mammalian central nervous system: dorsalventral patterning in the spinal cord, segmentation in the hindbrain, and lamination in the cerebral cortex. These strategies differ from one another in the cellular mechanisms used to achieve diversity, the degree to which cell fates are constrained by lineage or position, and the extent to which the molecular basis for determination is known.

There are two general mechanisms that contribute to the determination of specific neuronal fates. One is the inheritance by a cell of a restricted developmental potential from its parent or

I thank Amy Bohner for comments on the manuscript and Marianne BronnerFraser, Tom Jessell, and Chris Walsh for sharing results of experiments prior to publication. Supported by NIH EY08411, NIH MH51864, an NSF Presidential Faculty Fellow Award, and a McKnight Scholar Award.

Correspondence should be addressed to Dr. Susan K. McConnell at the above address.

Copyright (C) 1995 Society for Neuroscience 0270-6474/95/156987-12\$05.00/0 ancestor-in other words, the determination of cell fate by cell lineage. One can imagine two variations on this theme. Under the first, a distinct progenitor cell produces a distinct class of neurons. In this case, clones of related cells would be composed exclusively of neurons with a common phenotype. Under the second variation on the lineage theme, each precursor might generate neurons with a wide variety of phenotypes, but would do so following an intrinsic plan in which different cell types are generated in a predetermined pattern. In this scheme, the precursor is multifated (in the sense that it produces progeny that adopt a variety of fates), but lineage studies would reveal consistent patterns of clonal composition from animal to animal. Under the second mechanism that contributes to the determination of specific neuronal fates, neuronal precursors or their progeny are multipotent - that is, the cells may develop along a variety of possible pathways, and the particular pathway chosen results from interactions between cells and their local microenvironment. The environment is thought to provide instructive influences that actively signal or induce the production of specific neuronal phenotypes.

It is important to emphasize that lineage studies alone cannot reveal the mechanism by which a cell acquires its phenotype. Both variable and invariant lineages may result from extrinsic inductive events acting on multipotent cells. This apparent paradox is illustrated by studies of the nematode worm Caenorhabditis elegans, in which patterns of cell lineage are completely invariant from animal to animal (Sulston and Horvitz, 1977). This invariance led many to the premature conclusion that lineage-based inheritance provides the mechanism for cell fate determination. Cell ablation experiments, however, provided initially startling evidence that cell-cell interactions play a crucial role in the determination of many phenotypes - indeed, for many cells it seems that the role of lineage is to put the cell in the right place at the right time for these interactions to occur (Greenwald, 1989). Thus, to ascertain whether intrinsic or extrinsic influences determine a cell's fate, one must challenge the cell experimentally to change its normal fate by ablating its neighbors, by transplanting the cell into a foreign environment, or by mutating the animal's genotype (Stent, 1985).

\section{The Spinal Cord}

The spinal cord is a tube of cells composed of a relatively small number of neuronal phenotypes, with relatively minor regional heterogeneities along its anterior-posterior axis. The major axis of polarization is from dorsal to ventral, with motor neurons located ventrally and sensory neurons found dorsally in bilateral symmetry all along the length of the cord (Fig. 1). Spectacular 


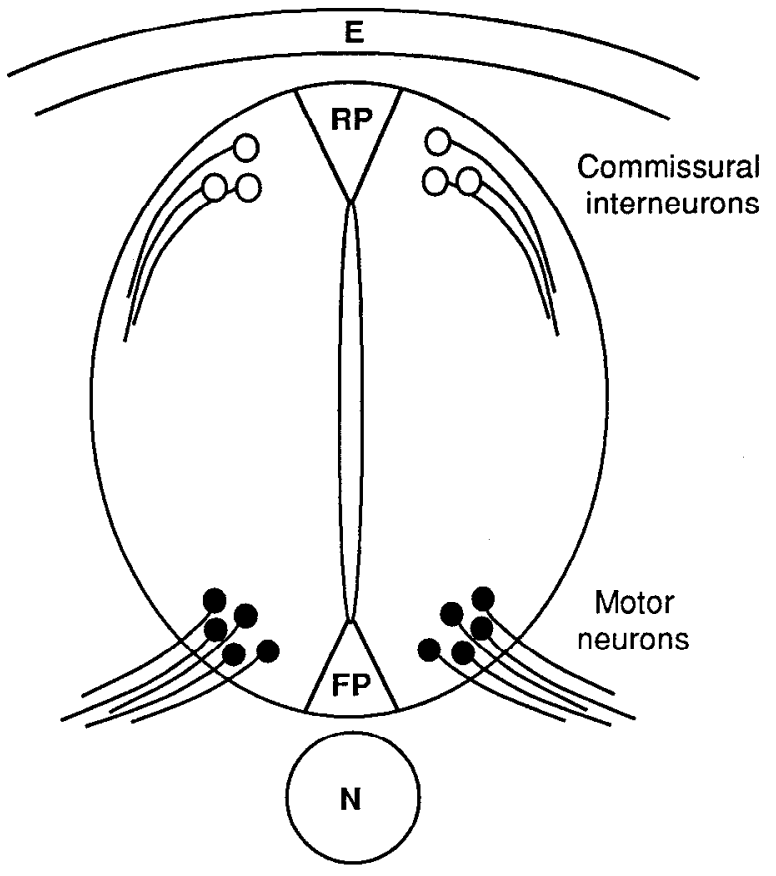

Figure 1. Dorsal-ventral patterning in the embryonic spinal cord. Commissural interneurons are located dorsally and project their axons ventrally (their complete axonal trajectories are not shown). Motor neurons are located ventrally on either side of the floor plate $(F P)$ and extend axons into the ventral roots. Abbreviations: $E$, ectoderm; $R P$, roof plate; $N$, notochord.

progress has been made at both the cellular and molecular levels in understanding the mechanisms by which dorso-ventral polarity is initially established in the spinal cord. It is by now well known that the chordomesoderm underlying the ventral spinal cord plays an essential role in the induction of ventral structures, including the floor plate and neighboring motor neurons. Extirpation of the notochord results in a failure of both floor plate and motor neurons to differentiate, while grafting an ectopic notochord induces the formation of an ectopic floor plate and accompanying set of motor neurons (reviewed by Dodd, 1992).

Dorsal cell types do not require signals from the notochord for their differentiation; indeed, in the absence of a notochord, dorsal cell types appear ectopically in the ventral spinal cord (Placzek et al., 1991; Yamada et al., 1991). These observations raise the possibility that dorsal fates constitute a default pathway for differentiation in the spinal cord. Alternatively, dorsal development may result from induction, with the notochord normally acting in ventral regions to repress the effects of dorsal inducers. Recent evidence supports that notion that dorsal cell fates are induced by signals from the overlying ectoderm, since coculturing ectoderm from very young embryos with neural plate induces the expression of a neural crest marker, the carbohydrate epitope HNK-1 (Selleck and Bronner-Fraser, 1995). Similar cocultures performed with slightly older tissues not only induce HNK-1, but also result in the induction of dorsal neural tube markers such as the wnt-1 protein (Dickinson et al., 1995). These data suggest that dorsal induction proceeds in at least two steps, the first resulting in neural crest formation and the second in dorsalization within the neural tube itself.

The dorsalizing and ventralizing signals may form opposing gradients of activity, the relative concentrations of which specify discrete cell fates along the dorsal-ventral axis (Basler et al.,
1993). The presence in the dorsal spinal cord of presumably secreted factors such as dorsalin-1, a member of the TGF $\beta$ family that promotes dorsal development and suppresses motor neuron differentiation (Basler et al., 1993), provides support for this view. In the absence of the notochord, dorsalin-1 expression extends ventrally, consistent with the appearance of dorsal cell types in ventral locations, and suggesting that the notochord normally represses dorsalin-1 expression in ventral regions. IIowever, implantation of a second notochord above the dorsal neural plate or tube fails to suppress the formation of dorsal structures such as the neural crest and commissural interneurons, which can emerge despite the production of ectopic ventral structures (Artinger and Bronner-Fraser, 1993b). Because dorsally grafted notochords do appear to repress the dorsal expression of both dorsalin-1 (Basler et al., 1993) and wnt-1 (M. Dickinson and M. Bronner-Fraser, unpublished observations), the persistent differentiation of the neural crest and commissural interneurons may have been stimulated by an earlier dorsalizing activity that is unaffected or insufficiently repressed by the ectopic notochord.

\section{Motor neuron induction}

The production of motor neurons in vivo requires a signal derived from a ventral source, since removal of the notochord blocks the formation of not only the floor plate but also motor neurons (Dodd, 1992; Yamada et al., 1993; but see Artinger and Bronner-Fraser, 1993a). These interactions can be reproduced in vitro: juxtaposition of a piece of notochord with an explant of lateral neural plate tissue, which would not on its own produce ventral cell types, induces the neural explant to form both floorplate and motor neurons, as assessed by the expression of markers specific to these ventral regions (Placzek et al., 1993; Yamada et al., 1993). While floorplate induction requires direct contact between notochord and neural tissue in vitro, the signal that induces the production of motor neurons appears to be diffusible (Placzek et al., 1993; Yamada et al., 1993). These observations have led to the suggestion that, in contrast to the notion that ventralization results from a single signal, the activities that regulate the production of the floor plate and motor neurons are distinct from one another. Both the notochord and the floor plate express closely-related homologs of the hedgehog gene of Drosophila, called sonic hedgehog ( $h h$ ) in chick (Echelard et al., 1993) and vertebrate hedgehog (vhh-1) in rat (Roelink et al., 1994), which show inductive activities in vivo and in vitro. COS cells expressing vhh-l induce floor plate and motor neuron differentiation in explants of neural plate, mimicking closely the action of the notochord under comparable circumstances (Roelink et al., 1994).

It is not completely clear whether the production of motor neurons in vivo is normally signalled by the notochord or by the floor plate, nor is it clear whether hedgehog homologs play a direct role in motor neuron induction. Both notochord and floor plate can induce motor neurons in vivo and in vitro; however, notochord transplantation, coculture of notochord and neural tissues, and expression of hedgehog homologs all typically result in the formation of a floor plate as well as motor neurons, leaving open the possibility that the notochord induces the floor plate, and the floor plate then secretes a further factor that specifies motor neurons. Several arguments have been made that the inductive activity is derived primarily from the floor plate. Clearly, the floor plate is sufficient to induce motor neurons, whether introduced by transplantation, in cocultures (Yamada et al., 1993), or simply by the addition of floor plate-conditioned me- 
dium (Roelink et al., 1994). In addition, ablation of half of the floor plate on either side of the midline in vivo results in a failure of motor neurons to differentiate on that side (Hirano et al., 1991). However, there is equally compelling evidence for a primary role for the notochord itself in regulating the formation of motor neurons. The notochord expresses $v h h-1$ before $v h h-1$ is turned on in the floor plate, and at a time when cells are already specified to become motor neurons (Roelink et al., 1994). Indeed, there is evidence that some cells have already adopted a motor neuron identity before the floor plate has been specified (Yamada et al., 1993). While the presence of the floor plate is sufficient for the genesis of motor neurons, it may not be necessary: motor neurons are present in roughly normal numbers in zebrafish carrying the cyclops mutation, in which the floor plate is absent (Hatta, 1991, 1992), and motor neurons arise in the chick after partial notochord ablations, in regions lacking a floor plate (Artinger and Bronner-Fraser, 1993a). In view of these findings, it seems reasonable to conclude that both the notochord and the floor plate are involved directly, and possibly sequentially, in motor neuron induction; however, the molecular mechanisms by which they accomplish this end may well be distinct from one another (Yamada et al., 1993).

\section{Cell lineage studies}

Cell lineage studies using retroviral lineage tracers suggest that neurons of the dorsal and ventral spinal cord are normally descended from separate pools of progenitor cells, located in the alar and basal plates, respectively (Leber et al., 1990). Since all regions of the spinal neural tube have the potential to produce motor neurons if presented with appropriate tissues or inducers, the generation of motor neurons from ventral progenitors presumably arises because of their proximity in vivo to the source of inductive activity. The precursor cells that generate motor neurons appear to be multipotent, since spinal motor neurons commonly share a lineage with a variety of other cell types, including not only motor neurons but also interneurons, autonomic preganglionic neurons, astrocytes, or oligodendrocytes (Leber et al., 1990). How ventral inducers effect the production of motor neurons from a multipotent progenitor cell is not known. One possibility is that the inducer is active only during the time in which motor neurons are generated; alternatively, the competence of cells to respond to the constitutive expression of motor neuron inducers may be regulated dynamically in space or in time. Motor neuron specification probably occurs prior to cell migration, since the onset of expression of the motor neuron marker Islet-1, a homeodomain gene of the LIM class, occurs soon after the cell's final mitotic division (Ericson et al., 1992). Whether it is the progenitor cell or the newly postmitotic neuron that responds to inductive signals is not yet known.

\section{Differentiation of specific motor neuron phenotypes}

Motor neurons are organized into two columns that course longitudinally on both sides of the spinal cord (refs. in Tsuchida et al., 1994). Both columns segregate cells according to their axonal projection patterns: neurons in the medial motor column innervate the axial musculature of the body wall, while cells in the lateral motor column project to the muscles of the limbs (Fig. 2). In addition, along the anterior-posterior axis of each column, motor neurons are segregated into motor pools that innervate specific muscle types. For example, within the lateral motor column, the most lateral motor pool innervates the muscles derived from the dorsal muscle mass of the limb, while the ventral mus-

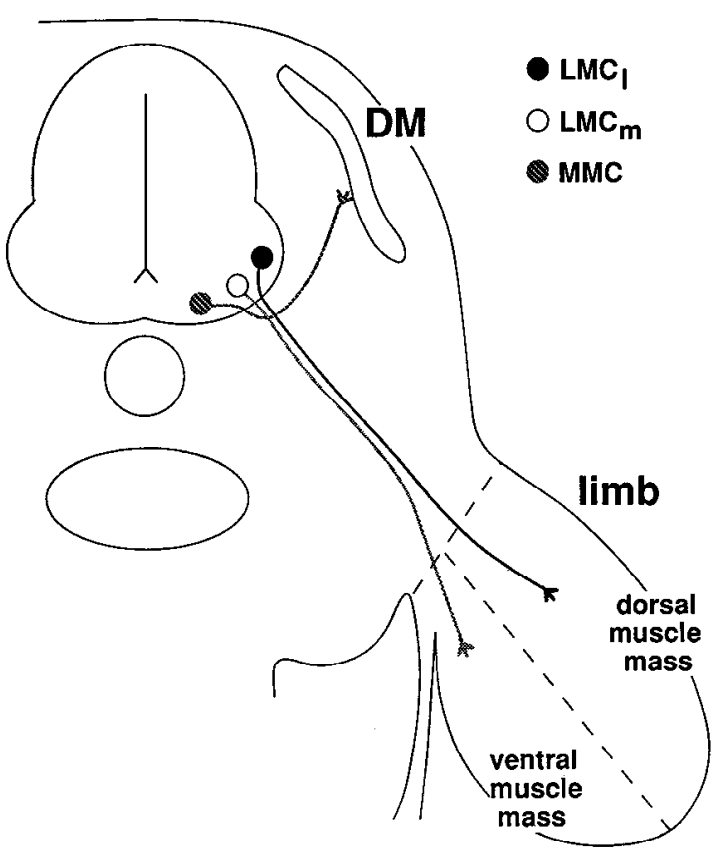

Figure 2. Organization of motor neurons at the brachial and lumbar levels of the developing spinal cord. Neurons of the medial motor column $(M M C)$ project axons into the dermamyotome $(D M)$, ultimately innervating the axial musculature. Neurons in the lateral subdivision of the lateral motor column $\left(L M C_{l}\right)$ project into the dorsal muscle mass of the limb, while neurons of the medial subdivision of the lateral motor column $\left(L M C_{m}\right)$ project to ventral muscles. Modified from Figure 8 in Tsuchida et al. (1994).

culature receives its inputs from more medial neurons. These neurons are generated at distinct times during development, with the production of medial neurons within the lateral column preceding that of more laterally located neurons. Lineage studies reveal, however, that clonally related motor neurons are commonly dispersed widely across the lateral motor column, and frequently even across the lateral and medial motor columns (Leber et al., 1990). These findings suggest strongly that clonally related neurons do not share common projection patterns: They may project to the axial or limb musculature, and, within the limbs, to either dorsal or ventral muscle masses.

Is the projection phenotype of a motor neuron then specified by the final position in which the cell finds itself after migration? Transplantation experiments in zebra fish have provided compelling evidence that individual primary motor neurons are committed to specific patterns of axonal projection by about an hour before the start of axogenesis, according to the position of the neuron one to two hours before the time of commitment (Eisen, 1991, 1994). However, earlier studies in the chick have provided tantalizing suggestions that motor neuron projection patterns may be determined long before the neurons arrive in their final positions. Here several spinal segments were rotated, reversing the anterior-posterior axis, then reimplanted; motor neurons innervated their muscle targets in a pattern that reflected their segment of origin and not their new position (I ance-Jones and Landmesser, 1980). Although rotation was performed before most motor neurons had been generated, it is possible that local cues were rotated as well and that the fates of individual motor neurons had not yet been specified (Eisen, 1994). Recent molecular studies provide indirect support for the notion of very early commitment to projection phenotype. Tsuchida and col- 
leagues (Tsuchida et al., 1994) have discovered an intriguing correlation between the expression of a family of LIM homeodomain genes and the projection patterns of motor neurons. Motor neurons present in distinct motor columns that share common patterns of axonal projections also express specific combinations of four LIM genes (Islet-1, Islet-2, Lim-1, and Lim-3). For example, neurons in the lateral portion of the lateral motor column (that project to the dorsal limb musculature) express Islet -2 and Lim-1, while ventrally projecting neurons located in the medial subdivision of the lateral motor column express Islet-2 and $I s$ let-I (Tsuchida et al., 1994). LIM gene expression in motor neurons occurs shortly after their birth, and long before these neurons innervate their distinct axonal targets. Within the medial motor column, Islet-1 is the earliest gene expressed, followed by Islet-2 then Lim-3; in the lateral motor column, Islet-l is also expressed first, followed by Islet-2 and Lim-1. Thus, it seems that specific patterns of LIM gene expression emerge prior to the formation of the lateral and medial subdivisions of the lateral motor column, suggesting (but not proving) that motor neuron identities have already been specified. Thus, contrary to the hypothesis that cell position determines projection phenotype, neurons may actively segregate into discrete columns according to previously determined phenotypes.

Whether the LIM homeodomain genes play a role in specifying the axonal pathways followed by motor neurons has not yet been tested by ectopic expression or gene knockout experiments. However, it is now clear that Islet-1, the earliest-expressed LIM gene, is required for normal motor neuron differentiation. In vitro treatment of neural tube explants that contain committed but undifferentiated motor neurons with antisense oligonucleotides to Islet-1 blocks not only the production of Islet-I protein, but also the formation of motor neurons; similarly, motor neurons are absent in mice in which the Islet-I gene has been knocked out (S. Pfaff, T. Edlund, and T. M. Jessell, personal communication).

Thus, while the spinal cord thus employs a seemingly simple strategy for the generation of dorsal and ventral neuronal phenotypes, in which inductive cues from the underlying notochord and possibly from the overlying ectoderm bias cells toward ventral or dorsal pathways, the mechanism by which discrete cell types are produced remains an enigma. The notochord and floor plate both serve as sources of diffusible signals that act on multipotent progenitors in the ventral neuroepithelium, triggering the production of motor neurons. Among these cells, neurons with distinct projection patterns are generated in a predictable sequence during development, then express specific combinations of LIM transcription factors prior to the time at which they extend axons. The factors that determine the axonal projections and patterns of gene expression of individual motor neurons remain a mystery.

\section{The Hindbrain}

The hindbrain is segmentally organized into rhombomeres during development (Fig. 3; for reviews, see Lumsden, 1990; Wilkinson and Krumlauf, 1990; Krumlauf et al., 1993; Keynes and Krumlauf, 1994). Neurons within each rhombomere develop in a manner that correlates with their axial level: for example, motor neurons within rhombomeres 2 and 3 contribute axons to the $V$ th cranial nerve, whereas the VIIth nerve is derived from neurons in rhombomeres 4 and 5 (Lumsden, 1990). Rhombomeres appear to fulfill several criteria that define them as developmental compartments. First, rhombomeres form domains for the expression

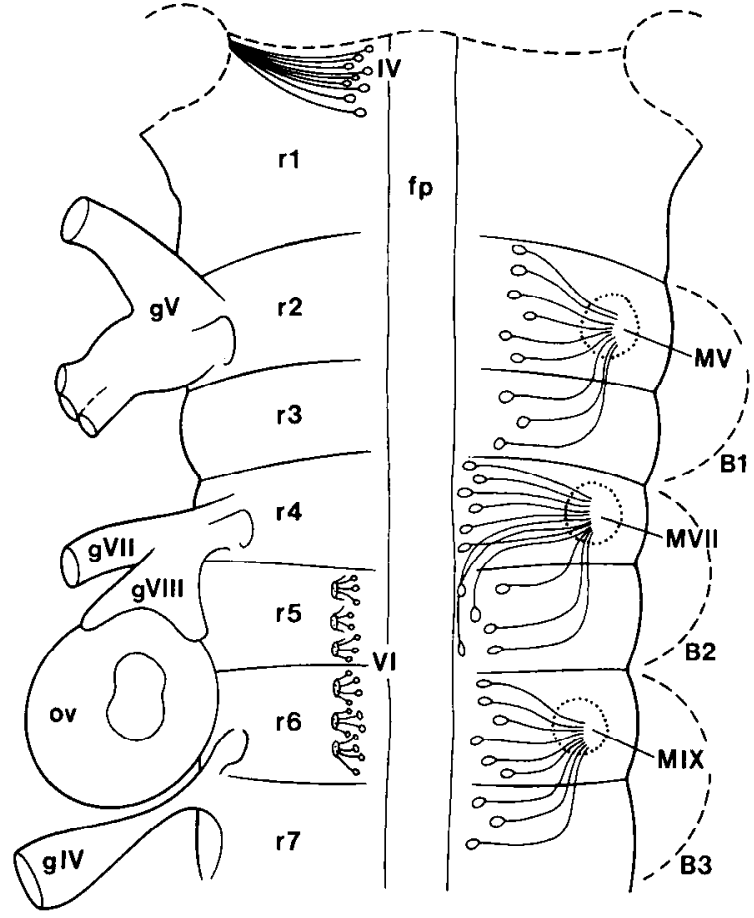

Figure 3. Segmental organization of rhombomeres in the hindbrain of a $3 \mathrm{~d}$ chick embryo (Keynes and Krumlauf, 1994). Abbreviations: $r l$ $r /$, rhombomeres $1-7 ; g V-g I X$, cranial sensory ganglia $V-I X ; B I-B 3$, branchial arches 1-3; $M V-M I X$, branchiomotor nerves; $O v$, otic vesicle; $f p$, floor plate. Reproduced, with permission, from the Annual Review of Neuroscience, Volume 17, copyright 1994 by Annual Reviews Inc.

of a variety of regulatory genes, including genes of the Hox cluster, as well as putative regulators of the Hox genes such as Krox 20 (Keynes and Krumlauf, 1994). These domains of gene expression, which are present within the neuroepithelium during times of neurogenesis, are thought to be critical for the control of segment-specific identity during development. Transplantation experiments show that rhombomeres retain their original positional identity in ectopic locations, expressing both an autonomous pattern of Hox gene expression and patterns of axonal outgrowth that are consistent with their origin (Guthrie and Lumsden, 1992; Kuratani and Eichele, 1993). Whether Hox genes control combinatorially the identity of individual rhomobomeres, however, remains controversial. The elimination of $H o x-A /$ by homologous recombination results in the abnormal development of the hindbrain - but rather than generating a homeotic transformation of rhombomere identity, rhombomeres 4 and 5 fail to develop properly and subsequently disappear (Carpenter et al., 1993; Dolle et al., 1993; Mark et al., 1993). Treatment with exogenous retinoic acid, however, alters the pattern of Hox gene expression and does appear to yield homeotic transformations, with rhombomeres 2 and 3 expressing properties typical of the more posterior segments 4 and 5 (Marshall et al., 1992).

The second line of evidence that rhombomeres are developmental compartments is that rhombomeres form discrete territories between which there is little cell mixing (Fraser et al., 1990). This segregation is apparently generated by differences in surface properties of cells in alternating rhombomeres. Rhombomere boundaries reform when rhombomeres from adjacent positions are transplanted next to one another, but not when two odd-numbered or two even-numbered rhombomeres are juxtaposed (Guthrie and Lumsden, 1991). Likewise, there is little cell 
mixing between adjacent odd- and even-numbered rhombomeres when a quail rhombomere is transplanted into a chicken host, whereas insertion of tissue from an equivalent rhombomere results in extensive intermingling of host and grafted cells (Guthrie et al., 1993). Recent cell lineage studies of DiI-labeled precursors in normal embryos have revealed, however, that some clones do indeed cross between adjacent rhombomeres, even after the formation of rhombomere boundaries (Birgbauer and Fraser, 1994). Since the boundaries of gene expression that distinguish adjacent rhombomeres are typically very sharp, it seems likely that cells that escape into adjacent rhombomeres regulate their patterns of gene expression to fit into the new environment, although it remains possible that they are recognized as deviant and ultimately eliminated. That the hindbrain has adopted some system for dealing with trespassers from neighboring segments makes even more compelling the case that strict boundaries of gene expression are essential for normal development and must be precisely maintained.

Most explorations of rhombomere development have emphasized anterior-posterior patterning, asking how, at a global level, differences between adjacent rhombomeres are generated and maintained during development. Molecular evidence indicates that early patterns of Hox gene expression are under the control of even earlier-expressed genes, such as Krox 20, and can be regulated by retinoids, which are thought to be present in these regions in vivo (reviewed in Keynes and Krumlauf, 1994; Krumlauf, 1994). Less attention has been paid to the generation of individual cell identities within and between these compartments. Each rhombomere contains a diversity of specific neuronal phenotypes, including a variety of peripherally projecting motor neurons and centrally or intrinsically projecting interneurons. While it may be the case the Hox gene expression determines the segment-specific identity of each rhombomere, it is not yet clear whether these same genes influence the processes by which a neuron initially acquires its identity as a motor neuron or interneuron, nor is it clear whether they influence directly the growth or guidance of axons to their segment-specific targets.

\section{Cell lineage studies}

Cell lineage studies have yielded somewhat conflicting answers to the question of whether lineage restricts cell fate decisions in the hindbrain. In one set of experiments, intracellular lineage tracer injections of single progenitors were performed in chick embryos at the onset of neurogenesis (stages 5-12, during the time in which rhombomere boundaries are forming) and analyzed shortly thereafter, between stages 13 and 20 (Lumsden et al., 1994). These injections yielded clones of neurons in which a majority (about $70 \%$ ) expressed a single, uniform phenotype as defined by the axonal trajectory of the labeled cells (Fig. 4). A clone might contain, for example, as many as a dozen branchiomotor neurons. In a substantial minority of clones $(17 \%)$, neurons adopted different but closely related phenotypes, such as neurons with axons that all entered the same major longitudinal tract but then coursed in different directions. Only about $11 \%$ of clones were comprised of neurons with markedly distinct phenotypes. Clones of neurons of one uniform phenotype occupied spatial domains that overlapped with clones of neurons of another phenotype; this spatial intermingling raises the possibility that the founder cell of each clone may have been specified to produce a single cell type (Lumsden et al., 1994). The presence of clones of neurons with closely related phenotypes also raises the possibility that specification involves several steps

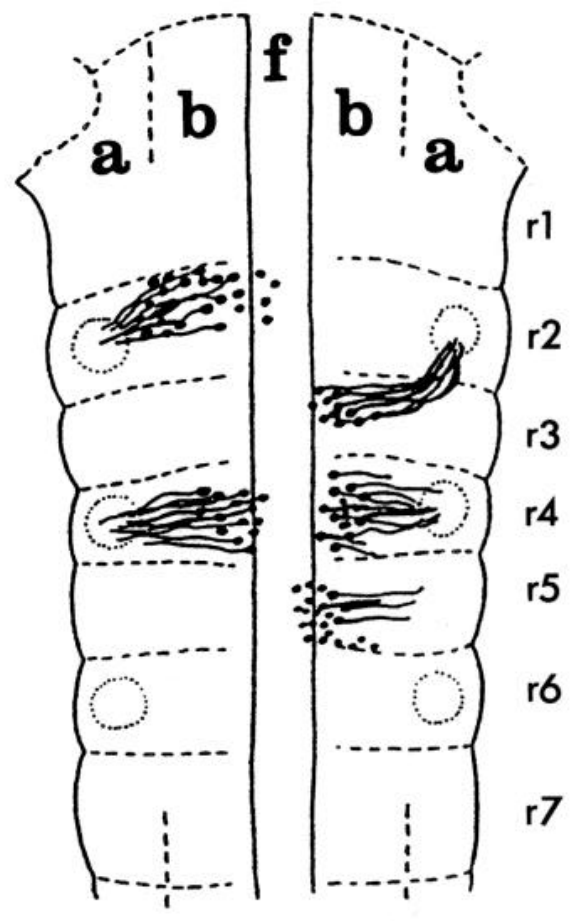

Figure 4. Clones consisting only of branchial motor neurons (brm) in the basal plate of single rhombomeres, superimposed on a diagram of the stage 19 chick hindbrain. Clones were labeled by intracellular injection of lysinated fluorescein dextran. Abbreviations: $f$, floor plate; $b$, basal plate; $a$, alar plate; $r l-r 7$, rhombomeres 1-7. Reproduced with permission from the Company of Biologists Limited (Lumsden et al., 1994; Fig. 3A).

or decisions, the first of which may be to become a motor neuron or an interneuron; only later might a neuron decide in which direction to extend its axon within a common pathway (Lumsden et al., 1994). It has not yet been possible to test directly the commitment of a clonal founder cell to generating one type of neuron, in part because there is no way to predict, on the basis of cell position or appearance, what type of clone it would generate under normal circumstances.

Clonal analysis at later stages in the hindbrain (Hemond and Glover, 1993) generates a quite different picture of the possible role of cell lineage in fate decisions, one that more closely approximates that seen in the spinal cord. When chicken embryos were infected with retroviral lineage tracers at later stages of neurogenesis (stages 13-17, just after all rhombomere boundaries have formed) and analyzed between stages 24 and 35, individual clones appeared to contain diverse neuronal phenotypes and were much more broadly dispersed in both the radial and tangential planes than the early-labeled clones of the study described above. Single progenitors even contributed progeny to more than one nucleus within the brainstem, and thus presumably generated a variety of functional types of neurons. Hemond and Glover (1993) concluded that the early clones described by Lumsden et al. (1994) derive mainly from founder cells undergoing proliferative (symmetric) divisions, generating large clones that tend not to disperse widely; later clones, in contrast, undergo primarily stem cell (asymmetric) divisions to generate smaller clones, which migrate radially away from the ventricular zone but then disperse tangentially, especially in lateral regions (Hemond and Glover, 1993). These late progenitors are presumably derived from the earlier precursor pools; indeed, Lumsden 
et al. (1994) found that their early clones often included not only neurons but apparently undifferentiated neuroepithelial cells, but they did not allow for long enough survivals to track the eventual fates of these cells. Thus late clones probably represent subclones derived from earlier progenitors, but they show markedly different patterns of proliferation and migration, and a less restricted range of phenotypic outcomes, than their earlier cousins.

\section{Differing strategies in early and late neurogenesis}

The specification of the identity of individual neurons in the hindbrain thus appears to be regulated by mechanisms that vary over time. Early influences from the midline, including the chordomesoderm, floor plate, and possibly the dorsal ectoderm, may set up dorso-ventral polarity within each rhombomere (Lumsden et al., 1994), in a manner similar to that already discussed for the spinal cord. Lumsden et al. (1994) suggest, however, that individual precursors that have responded to inductive cues now become refractory to further inductive input and undergo several rounds of cell division, generating neurons of a common phenotype. During this period, only a restricted set of fates are adopted by each precursor cell, despite the intermingling of the precursor and its progeny with neighboring cells. Later, however, as development proceeds, cells that remain in a proliferative state undergo two changes. First, they seem to undergo fewer proliferative divisions (and thus produce a smaller number of progeny), and second, they seem to reenter a period in which they are capable of producing a variety of neuronal types (Hemond and Glover, 1993), possibly doing so once again under the influence of cell-cell and environmental interactions (Lumsden et al., 1994).

As was emphasized in the introductory section, these conclusions are largely speculative, since the commitment of any of these cells to generating neurons of the same or diverse phenotypes has yet to be tested directly. The finding that at least some cells in clones marked after the formation of visible rhombomeres can cross the boundary into an adjacent rhombomere raises the possibility that there is more developmental plasticity in the hindbrain than has been assumed previously, although it is not yet known whether cells that wander into neighboring segments ultimately die or transform their identities. All the transplantation experiments published to date have considered the development of groups of cells (whole or half rhombomeres), and have emphasized the cell-autonomy of their patterns of gene expression and contributions to cranial nerves (Guthrie and Lumsden, 1991; Guthrie and Lumsden, 1992; Kuratani and Eichele, 1993). Perhaps individual cells, in contrast to groups of cells, that cncounter a novel environment would be more motivated to fit into the picture, since community effects and homeogenetic inductions by which neighboring cells reinforce one another's differentiation are well known in developing systems (Gurdon, 1988; Placzek et al., 1993).

The strategy used by the hindbrain to generate neuronal diversity appears to be akin to that used in insect development, in which segmentally reiterated units are erected early in development as common themes on which to construct later variations. As in insects, early cell lineage patterns in the hindbrain may be more rigid or restricted than elsewhere in the vertebrate CNS, reinforcing the notion that the hindbrain employs a set of "ancestral developmental strategies" (Lumsden et al., 1994) to accomplish its early patterning. Whether these strategies set the hindbrain apart from other regions of the neural tube remains to be seen, although the results of several studies suggest already that the vertebrate forebrain is segmentally organized (Figdor and Stern, 1993; Puelles and Rubenstein, 1993).

\section{The Cerebral Cortex}

A third common pattern seen in the vertebrate CNS is the construction of layers, which are apparent in regions such as the cerebral cortex, retina, tectum, and cerebellum. Layers typically segregate neurons that share characteristic dendritic morphologies, physiological properties, and axonal connections (reviewed in McConnell, 1988a, 1991). Unlike the retina and tectum, however, the cerebral cortex is also broken up in the tangential plane into functionally distinct areas, each subserving a specific function, such as the analysis of incoming sensory information and the coordination of motor outputs. Each area is also characterized by distinctive cytoarchitectonic features (Brodmann, 1909), and the axonal connections of neurons in different areas reflect their functional specificity. The cerebral cortex appears to use different mechanisms to generate order and pattern in the radial and tangential domains.

\section{Cell lineage studies}

The analysis of lineage relationships among cortical cells has proven much more complex than in other regions. Studies using retroviral lincage tracers suggest that clonally related cortical cells can spread extensively throughout the cortex, with clones dispersed even among distinct areas (Walsh and Cepko, 1992). This interpretation is supported by the direct demonstration that neurons can migrate tangentially within the intermediate zone (O'Rourke et al., 1992, 1995) and by evidence suggesting that progenitor cells disperse laterally within the ventricular zone (Fishell et al., 1993). The tangential dispersion of both progenitors and postmitotic neurons means that a clone cannot be accurately defined as a spatially restricted cluster of cells, an operational definition that has served well in other systems, including other layered structures (Turner and Cepko, 1987; Wetts and Fraser, 1988; Holt et al., 1988; Galileo et al., 1990; Leber et al., 1990). Only recently have investigators begun to use large libraries of retroviral vectors that allow individual infected cells to be assigned accurately to clones regardless of their position.

In many regions of the CNS, including a varicty of layercd structures, common progenitors produce both neurons and glial cells (Turner and Cepko, 1987; Holt et al., 1988; Wetts and Fraser, 1988; Galileo et al., 1990; Leber et al., 1990). Studies of the developing cerebral cortex have suggested, however, that neurons, astrocytes, and oligodendrocytes derive from largely separate lineages (Levitt et al., 1981; Luskin et al., 1988; Price and Thurlow, 1988; Grove et al., 1993). It should be noted that all of these studies have used spatial criteria to assign clustered cells to clones. Since little is known about the migration patterns of glia or their progenitors, it remains possible that distant clusters of neurons and clusters of glia could share a common progenitor cell if the daughters of the progenitor were to move apart and then subsequently produce subclones of purely neurons and purely glia. Indeed, it is thought that tightly clustered groups of astrocytes within the cortex are generated from a progenitor cell that itself migrates into the cortical plate then divides several times in situ to generate a cluster of glia (Luskin et al., 1988).

Evidence has also been put forward that the lineages for two different types of neurons, excitatory projection neurons and inhibitory interneurons, separate early in development, prior to the onset of neurogenesis (Parnavelas et al., 1991; Mione et al., 1994). These results have led to the inference that, in cortical develop- 
ment, excitatory and inhibitory neurons are derived from separate lineages. Again, however, these studies have relied on spatial clustering to assign cells to clones. A recent study using a library of retroviral vectors to determine clone composition suggests that the story is even more complicated than thought previously. Reid et al. (1995) have suggested that cortical progenitor cells can migrate through the ventricular zone, stopping occasionally to produce a nonmigratory progenitor cell. This latter cell can divide to produce a small clone of cortical neurons that are typically clustered within $0.5 \mathrm{~mm}$ of one another; such clustered cells commonly sit in the same or an adjacent layer of cortex and share a common (either pyramidal or nonpyramidal) morphology. In the meantime, the migratory sibling of the stationary progenitor may have moved to a distant site, there generating another nonmigratory cell, which itself divides to produce a small clone. The members of this clone are also similar to one another, but often have quite distinct laminar and morphological properties from their faroff cousins (Reid et al., 1995). These studies suggest that there is a common (migratory) precursor for both projection neurons and interneurons, but that sublineages of these two cell types can emerge when progenitor cells remain stationary and their progeny clustered. Consistent with this view, experiments in which cortical cells were studied in culture reveal that clones are commonly composed of both GABAergic (inhibitory) interneurons and glutamatergic neurons (Götz et al., 1995). Whether there is a subclonal, progressive commitment of precursors to the generation of one type of cell or the other in vivo remains to be tested directly.

\section{Asymmetric cell divisions within the cerebral ventricular zone}

Among neuronal lineages, clones have generally been reported to be small, although an accurate assessment of clone size is made difficult by the dispersion of clonally related cells over wide expanses of cortical territory (Walsh and Cepko, 1992). The findings that neuronal clones commonly span several cortical layers (Luskin et al., 1988; Price and Thurlow, 1988; Walsh and Cepko, 1988; Price et al., 1991) and that cells of different layers are generated sequentially (see below) have generated the hypothesis that many, or perhaps even most, cell divisions that produce neurons are asymmetric in nature. This hypothesis is supported by the observation of two distinct types of division among cortical progenitor cells (Chenn and McConnell, 1995). In the first type of division, which appcars morphologically symmetric, clcavage bisects the progenitor into two daughters at an angle perpendicular to the ventricular surface. After division, the two daughter cells maintain close contact with one another and their nuclei move slowly out toward the pial surface at the rate associated with a cell in the G1 phase of the mitotic cycle, readying itself to enter S-phase. The second type of division, which occurs with increasing frequency as neurogenesis proceeds, is morphologically asynmetric: cleavage occurs parallel to the the ventricular surface, generating an apical and a basal daughter. In the majority of such divisions, the two daughters then separate from one another, with the basal (pial) daughter moving rapidly out of the ventricular zone at a velocity typical of a young migrating neuron (O'Rourke et al., 1992). These observations raise the possibility that the orientation of the cleavage plane may determine whether a cell reenters or exits the cell cycle following mitosis.

Among higher eukaryotes, the molecular mechanisms underlying asymmetric cell divisions have been explored most thoroughly in Drosophila. Intrinsic determinants of cell fate that are inherited or localized asymmetrically include the protein products of the numb and prospero genes (Rhyu et al., 1994; E. Spana and

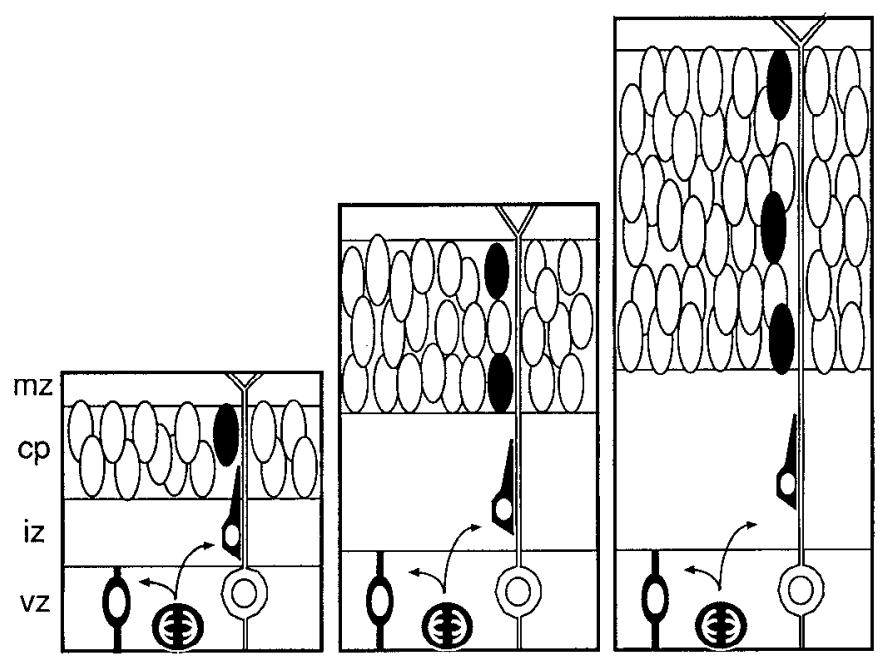

Figure 5. The generation of cortical neurons in an inside-first, outsidelast gradient. The neurons born within the ventricular 7one $(v z)$ are destined for the deepest layers of the cortical plate $(c p)$. Subsequently generated neurons migrate past the older cells, progressively forming the morc superficial cortical layers. Evidence from cell lineage experiments indicate that clonally related neurons (darkened cells) can span several cortical layers, suggesting that precursor cells may often divide asymmetrically within the ventricular zone. Note that not all clones in lineage studies are clustered radially, as shown here. Abbreviations: $m z$, marginal zone (future layer 1 ); $i z$, intermediate zone.

C. Doe, personal communication). Although it is not yet known whether mammalian CNS progenitors express homologs of either of these proteins, cerebral ventricular cells do express Notchl, one of several mammalian homologs of the neurogenic gene Notch in Drosophila (Weinmaster et al., 1991). An antibody to the intracellular domain of the Notch1 protein has revealed that Notch1 staining is localized asymmetrically in cortical progenitor cells, concentrated at the basal (pial) surface of mitotic cells (Chenn and McConnell, 1995). This basal distribution of immunoreactivity results in the differential distribution Notchl to the basal (neuronal) daughters generated from asymmetric divisions. The asymmetric inheritance of Notch1 may provide or contribute to a molecular mechanism for producing two distinct cell types from a common progenitor, although it is surprising in this light that Notch activity has been associated with the suppression of neuronal differentiation in vertebrate systems (Coffman et al., 1993; Nye et al., 1994; Dorsky et al., 1995).

\section{The production of layer-specific neuronal phenotypes}

${ }^{3} \mathrm{H}$-Thymidine birthdating studies in the developing cerebral cortex have shown that precursors sequentially produce neurons destined for the six layers in an inside-first, outside-last manner (Fig. 5; Angevine and Sidman, 1961; Berry and Rogers, 1965; Rakic, 1974). Other layered structures produce different neuronal phenotypes in a stereotypic order as well (Gray et al., 1990; Harris and Holt, 1990). The correlation between a neuron's birthdate and its ultimate laminar destination has made it possible to test the relative contributions of cell lineage and cell environment to the establishment of layer-specific phenotypes (McConnell, 1988b; McConnell and Kaznowski, 1991). Could a cell's birthday in some way determine its fate? Although neurons of the different cortical layers appear to be generated from a common set of progenitor cells, it seems possible that cortical progenitors are preprogrammed first to produce neurons of the deep layers, then middle-layer cells, and finally upper-layer neu- 


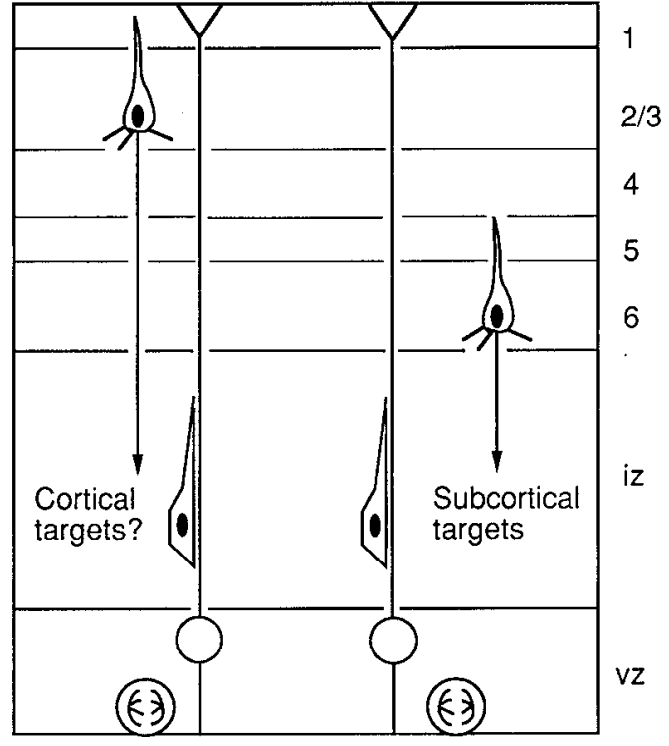

A. Cells transplanted in S-phase: daughters adopt host fate
B. Cells transplanted at or after G2: daughters are committed to deep layer fate

Figure 6. Outcomes of transplanting presumptive layer 6 neurons into an older host brain, in which upper-layer neurons are being generated. $A$, If environmental factors determine laminar fate, transplanted neurons should adopt the host fate by migrating to the upper layers 2 and 3 , and extending their axons to cortical targets. This is the result obtained when progenitor cells are transplanted during S-phase of the cell cycle and the fates of the daughters produced from the subsequent mitotic division are traced. It is not yet known whether these transplanted neurons also adopt the axonal connections typical of normal layer $2 / 3$ neurons. $B$, Transplanted cells that are committed to their normal laminar fates develop autonomously within the novel environment, migrating to layer 6 (the destination appropriate for their birthdate) and forming subcortical projections. This is the outcome of transplantation experiments in which progenitors are transplanted at any time at or after the transition into G2 of the cell cycle. Modified from Figure 1 in McConnell and Kaznowski (1991).

rons, following an intrinsic developmental clock. Alternatively, environmental signals that change progressively over the course of development might interact with multipotent cortical cells to specify different phenotypes.

It was possible to distinguish between these two alternatives by transplanting progenitur cells that normally produce deeplayer neurons into older host brains, and by performing the these transplantations at different stages of the cell cycle (McConnell and Kaznowski, 1991). When progenitor cells are transplanted during S-phase, they are multipotent: their daughters, which have completed their final cell cycle in an older environment, take on a novel fate and migrate to the upper cortical layers, along with newly generated host neurons (Fig. 6A). Thus, environmental cues can exert a determinative effect on laminar phenotypes, since the fates of early progenitors can be altered if the cells are transplanted early in the cell cycle. The multipotency of progenitors, however, is lost as the cell progresses through the cell cycle: precursors transplanted late in the cell cycle produce daughters that migrate specifically to layer 6 , the layer appropriate for their birthdate (Fig. 6B). Thus laminar commitment occurs prior to the mitotic division that generates the postmitotic cortical neuron. These studies suggest that there is a cell-cycle dependent plasticity within the cortical ventricular

zone: progenitor cells in S-phase of the cell cycle are multipotent and can give rise to daughters with various laminar phenotypes. This period of plasticity is transient, however, and the progenitor makes a commitment to the fate of its daughter at roughly the time it transits into the $\mathrm{G} 2$ phase of the cell cycle. Cells transplanted at or after this point are endowed with the information they need to produce daughters that home to the cortical layer appropriate for their birthdate and form axonal projections characteristic of that layer.

The molecules that specify particular laminar fates have not yet been identified. However, current evidence indicates that cell-cell interactions are essential to the acquisition of a deeplayer identity (Bohner and McConnell, 1993; Bohner et al., 1995). When S-phase cells are dissociated and maintained at low density in culture during the critical window of the cell cycle in which cell fate decisions occur, their daughters fail to commit to their normal deep-layer fates, suggesting that the deep-layer phenotype does not constitute a default pathway for differentiation. Reaggregation of dissociated progenitors during this critical window of the cell cycle partially restores normal commitment, presumably due to the restoration of cell signalling. Finally, a normal extent of deep-layer commitment is observed when progenitor cells are maintained in explants that preserve the normal relationships between cells. This progressive restoration of commitment to the deep-layer fate suggests that spatially ordered signaling systems provide inputs to multipotent progenitors that determine the laminar fates of their daughters.

In vivo, previously generated differentiating neurons may provide a possible source of environmental input to progenitor cells during S-phase. According to this proposal (previously framed for retinal neurogenesis by Reh and Tully, 1986), there may be a feedback control over neurogenesis such that the act of producing neurons of a given layer might feed back onto progenitor cells, in effect signaling "enough of this layer, get on with the next." Evidence consistent with this proposal has recently been obtained by Gillies and Price (1993). They interfered with the production of deep-layer neurons in the mouse by treating young embryos with the cytotoxic drug methylazoxymethanol acetate, which kills dividing precursor cells. The ventricular zone recovered from drug treatment over the next few days, but instead of resuming its normal schedule of laminar production, the system regulated and replaced the missing deep-layer neurons. The resulting cortex was thinner and contained fewer cells overall, but all of the layers and their axonal projections were present.

What might be the cellular source of a feedback signal from differentiating neurons in the cortical plate to cortical progenitors? The developing axons and growth cones of cortical neurons have been traced by injecting Dil into the preplate or cortical plate of fixed embryos (Kim et al., 1991; Bicknese et al., 1994; McConnell et al., 1994). These studies have revealed that, along the initial part of their trajectory, cortical growth cones travel directly along the surface of the ventricular zone-notably, just above the very region where the cell bodies of multipotent cortical progenitor cells are found. This juxtaposition of growing axons and precursor cell bodies raises the possibility that axons deliver a feedback signal from differentiating neurons in the cortical plate to the progenitor cells below, a hypothesis that remains to be tested directly.

On the whole, these results indicate that the layered patterning of cerebral cortical neurons arises through a progressive specification of ccll types, presumably cffected by changes in the nature of environmental cues over time in development. It 
should be noted, however, that these findings do not rule out intrinsic changes in cortical progenitors over time, since the transplantation studies discussed above examined the developmental potential only of early precursor cells that are normally fated to produce cells of multiple cortical layers (Luskin et al., 1988; Price and Thurlow, 1988; Walsh and Cepko, 1988; Austin and Cepko, 1990). It remains possible that late progenitors, which normally produce only upper-layer neurons, may have a more restricted developmental potential; this can be tested by transplanting late progenitors into younger brains. Preliminary results from such heterochronic transplants suggest that late cortical progenitors will produce only upper-layer neurons, even in a much younger environment, consistent with the interpretation that late progenitors have lost the competence to produce earliergencrated phenotypes (Frantz ct al., 1995).

\section{Molecular basis of laminar determination}

Several lines of evidence suggest that molecular differences among layers should be apparent early in development (Shatz, 1992). First, transplantation studies show that the laminar identities of cortical neurons are determined early in development, during their final cell cycle just prior to mitosis (McConnell, 1988b; McConnell and Kaznowski, 1991). Thus, committed premigratory cells are present within the cerebral ventricular zone. Second, migrating cortical neurons can home to the correct layer, actively recognizing their appropriate laminar address (McConnell, 1988b; McConnell and Kaznowski, 1991). Third, the axons of cortical neurons extend toward specific targets from the outset of their development (Katz, 1991; Koester and O'Leary, 1993), and neurons in cortical explants make lamina-specific choices of what are normally their long-distance targets in cocultures (Bolz et al., 1990; Yamamoto et al., 1992). Thus the migration, axonal pathfinding, and target selection of neurons in the different layers are strikingly distinct from the earliest times studied, which implies that there must be early molecular distinctions between layers.

One of the first studies to provide evidence for molecules that might specify laminar differences was performed by $\mathrm{He}$ et al. (1989), who identified a family of POU homeodomain genes that are expressed in the mammalian CNS, a subset of which are expressed preferentially in the upper or deep layers of the cortex. POU genes are known transcriptional regulators that contain both a homeodomain and a POU-specific domain (Herr et al., 1988; Rosenfeld, 1991; Schöler, 1991), and have been directly implicated in cell fate decisions in the nematode $C$. elegans (Finney et al., 1988) and in the mammalian pituitary (Bodner et al., 1988; Ingraham et al., 1988; Li et al., 1990; Pfaffle et al., 1992). One of these genes, variously known as Tst-1 (He et al., 1989), SCIP (Monuki et al., 1989), or Oct-6 (Suzuki et al., 1990), is expressed specifically by the neurons of the deep cortical layers 5 and 6 , from the time of their initial migration into the cortical plate through adulthood, when it is present specifically in those neurons that make subcortical axonal connections (Frantz et al., 1994). Another putative transcriptional regulator, Otxl, one of two vertebrate homologs to the Drosophila homeodomain gene orthodenticle, is also expressed in a subset of layer 5 and 6 neurons from the earliest times they are present into adulthood (Frantz et al., 1994). Otxl is expressed at high levels by early cortical progenitors at the time of deep-layer neurogenesis, but is apparently downregulated later when upperlayer neurons are being born. This loss of OtxI expression in late precursors correlates with their apparently restricted devel- opmental potential, as revealed by transplantation studies. The possibility that OtxI regulates deep-layer fates in the cortex remains to be tested by altering patterns of $O t x l$ expression.

\section{The formation of cortical areas}

In contrast to the hindbrain, neocortical areas probably do not employ a compartmental strategy for development. Boundaries between different cortical areas do not appear to be strictly determined at early ages, since cell mixing can occur between areas (O'Rourke et al., 1992; Walsh and Cepko, 1992; Fishell et al., 1993), and cortical areas have a broad developmental potential, as assessed in transplantation experiments (see below). No areaspecific patterns of regulatory gene expression have yet been described (although it is conceivable that such genes will be identificd in the future, and "nested" patterns of gene expression have been described in the cortex by Simeone et al., 1992a). Thus, one may (arguably) view the neocortex as one large developmental compartment within the forebrain; differences among cortical areas appear to emerge later in development through a series of epigenetic interactions (reviewed in McConnell, 1992; Shatz, 1992). Nevertheless, the neocortex as a whole appears to be distinct from adjacent forebrain regions relatively early in development (Puelles and Rubenstein, 1993): It expresses several potential regulatory genes including $E m x-1$ and $E m x-2$ (Simeone et al., 1992b), which are not expressed in the basal ganglia or piriform cortex. In a complementary manner, genes such as $D l x-1$ and $D l x-2$ are expressed in ventral forebrain, including the developing basal ganglia, but not in neocortex (Porteus et al., 1991; Price et al., 1991, 1992). The apparent molecular boundary between neocortex and the developing striatum also appears to be a boundary that restricts cell movement, since video imaging studies of migrating ventricular cells show that cells which approach the ganglionic eminence (the striatal anlage) will not cross into this region (Fishell et al., 1993). Surprisingly, even though cells prefer not to cross this boundary, striatal cells transplanted into the neocortex develop morphologies and connections typical of their new location (Fishell, 1995).

The developmental potential of neocortical neurons to assume the projection patterns and cytoarchitectonic features of other areas has been tested directly in transplantation experiments; the results of these studies have generated a complex picture of how areas form. Occipital cortical neurons transplanted to rostral cortex alter their pattern of long-distance projections to innervate targets appropriate for their new position, and transplanted pieces of occipital cortex are capable of forming barrel fields when transplanted into the somatosensory cortex of the host brain (Stanfield and O'Leary, 1985; O'Leary, 1989; O'Leary and Stanfield, 1989; Schlagger and O'Leary, 1991). These studies suggest that the fetal neocortex is functionally equipotential throughout its tangential extent, and that the identity of each cortical area is specified by the pattern of thalamic afferent input that it receives (O'Leary et al., 1994). Contrasting results have been obtained from transgenic mice in which regulatory elements from a major histocompatibility complex gene were linked to a lac $Z$ reporter gene; these mice showed a variety of insertion site effects on the patterning of transgene expression (Cohen-Tannoudji et al., 1994). In one line of mice, the lacZ gene is (surprisingly) expressed specifically in the somatosensory cortex. When somatosensory cortex from a fetal transgenic donor is transplanted to the occipital region of a wild type host, the transplanted tissue maintains its cell-autonomous pattern of lacZ gene expression (Cohen-Tannoudji et al., 1994), suggesting 
that at least some area-specific features of cortex are specified early in development. In addition, transplantation studies in which frontal cortex is replaced by implants of either frontal or occipital cortical tissue show that functional recovery from the lesion is obtained only when the transplanted tissue is derived homotopically (Barth and Stanfield, 1994). Finally, limbic cortical regions display a commitment to area-specific patterns of genc cxpression, and to at least some features of conncctivity, when transplanted into the developing neocortex (Barbe and Levitt, 1991, 1992).

The results from transplantation experiments thus suggest that while the neocortex can show remarkable plasticity in its axonal connections and cytoarchitectonic features, positional differences do exist in the embryonic cortex at times prior to the emergence of area-specific features. The molecular underpinnings of these differences remain unclear. At a cellular level, however, recent experiments implicate the transient neurons of the cortical subplate in the development of area-specific patterns of connectivity. When subplate neurons are pharmacologically ablated early in development, thalamic axons fail to recognize and innervate their appropriate cortical targets, and instead grow past their normal terminal destination (Ghosh et al., 1990; Ghosh and Shatz, 1993). It has been suggested that the positional cues that delineate distinct areas may reside in the subplate (Ghosh and Shatz, 1993; O'Leary et al., 1994). Regional differences among subplate neurons may control the area-specific targeting of thalamic axons into the cortex; these afferent axons subsequently influence the differentiation of area-specific features within the cortical plate.

To summarize, the layers of cortical neurons are generated from a neuroepithelial sheet in which there appear to be few differences in the precursor population across the tangential extent of the sheet, even though a variety of progenitor types may intermingle and coexist within the ventricular zone. Transplantation experiments demonstrate directly that early cortical progenitors are multipotent with respect to the laminar fates of their daughters, but suggest that developmental potential narrows as corticogenesis proceeds. In contrast to the spinal cord and hindbrain, in which the production of distinct cell types is influenced by spatially segregated inducers, such as the ventral notochord and floor plate, the cortex (and most other laminar structures) sequentially generates different cell types from a common spatial origin. Thus, it is plausible that the mechanisms that underlie this production line are temporally rather than spatially regulated. An obvious candidate source of temporally varying cues is the cortical plate itself, but the hypothesis that neurogenesis is regulated by feedback from recently generated neurons remains to be tested directly. The production of a common set of cortical layers throughout the cortex forms a scaffold from which areaspecific differences can later emerge.

\section{Conclusions}

While one might have thought that the vertebrate nervous system uses a single, unifying strategy across all its different regions for the production of the broad range of neuronal phenotypes, the developing brain and spinal cord clearly deploy a wide variety of cellular and molecular mechanisms for generating diversity. Moreover, many mechanisms can come into play even within a single region, at different times during development or at slightly different locations. The presence of spatially localized inductive activities in the spinal cord appears to mold the regional flavor of the cord and stimulate the production of motor neurons in a specific location, but cannot explain the orderly production of neurons with distinct axonal trajectories and their correlated patterns of gene expression. While early cell lineages in the hindbrain may be restricted to a single phenotype, later lineages become highly variable. In the cortex, an early commitment to lamina-specific fates contrasts sharply with the extended plasticity seen in the same cells after their migration into the neocortex with respect to their area-specific projections. There is as yet no sign that we have exhausted the repository of neurodevelopmental mechanisms-every exploration of a different set of neurons seems to add a new twist on the previously known themes of the governance of phenotype by a cell's ancestry or by its local interactions. It -seems that no single set of neurons within the CNS serves as an adequate model system to explain the rest, except pechaps in representing the range of mechanisms and options that are available throughout the nervous system as it generates both pattern and detail. Indeed, as each new study provides us with different insights into the possibilities, these insights continue to refocus our vision of the developing nervous system as the most amazing assemblage of cells known to nature.

\section{References}

Angevine JB Jr, Sidman RL (1961) Autoradiographic study of cell migration during histogenesis of cerebral cortex in the mouse. Nature 192:766-768.

Artinger KB, Bronner-Fraser M (1993a) Delayed formation of the floor plate after ablation of the avian notochord. Neuron 11:1147-1161.

Artinger KB, Bronner-Fraser M (1993b) Notochord grafts do not suppress formation of neural crest cells or commissural neurons. Development 116:877-886.

Austin CP, Cepko CL (1990) Ccllular migration patterns in the developing mouse cerebral cortex. Development 110:713-732.

Barbe MF, Levitt P (1991) The early commitment of fetal neurons to limbic cortex. J Neurosci 11:519-533.

Barbe MF, Levitt P (1992) Attraction of specific thalamic input by cerebral grafts depends on the molecular specificity of the implant. P roc Natl Acad Sci USA 89:3706-3710.

Barth TM, Stanfield BB (1994) Homotopic, but not heterotopic, fetal cortical transplants can result in functional sparing following neonatal damage to the frontal cortex in rats. Cereb Cortex 4:271-278.

Basler K, Edlund T, Jessell TM, Yamada T (1993) Control of cell pattern in the neural tube: regulation of cell differentiation by dorsalin-1, a novel TGF beta family member. Cell 73:687-702.

Berry M, Rogers AM (1965) The migration of neuroblasts in the devcloping cercbral cortcx. J Anat 99:691-709.

Bicknese AR, Sheppard AM, O'Leary DD, Pearlman AL (1994) Thalamocortical axons extend along a chondroitin sulfate proteoglycanenriched pathway coincident with the neocortical subplate and distinct from the efferent path. $J$ Neurosci 14:3500-3510.

Birgbauer E, Fraser SE (1994) Violation of cell lineage restriction compartments in the chick hindbrain. Development 120:1347-1356.

Bodner M, Castrillo J-L, Theill LE, Deerinck T, Ellisman M, Karin M (1988) The pituitary-specific transcription factor GHF-1 is a homeobox-containing protein. Cell 55:505-518.

Bohner AP, McConnell SK (1993) Cortical neuronal progenitor cells can become committed to a laminar fate in vitro. Soc Neurosci Abstr 19:638.

Bohner AP, Akers RM, McConnell SK (1995) Short-range cues are required for cortical decp-layer specification in vitro. Soc Neurosci Abstr 21:780.

Bolz J, Novak N, Götz M, Bonhoeffer T (1990) Formation of targetspecific neuronal projections in organotypic slice cultures from rat visual cortex. Nature 346:359-362.

Brodmann K (1909) Lokalisationslehre der Groshirnrinde in ihren Principen dargestellt aus Grund des Zellen baue. Leipzig: Barth.

Carpenter EM, Goddard JM, Chisaka O, Manley NR, Capecchi MR (1993) Loss of Hox-A1 (Hox-1.6) function results in the reorganization of the murine hindbrain. Development 118:1063-1075.

Chenn A, McConnell SK (1995) Cleavage orientation and the asym- 
metric inheritance of Notch1 immunoreactivity in mammalian neurogenesis. Cell 82:631-642.

Coffman CR, Skoglund P, Harris WA, Kintner CR (1993) Expression of an extracellular deletion of Xotch diverts cell fate in Xenopus embryos. Cell 73:659-671.

Cohen-Tannoudji M, Babinet C, Wassef M (1994) Early determination of a mouse somatosensory cortex marker. Nature 368:460-463.

Dodd J (1992) Mesodermal control of neural cell identity in vertebrates. Curr Opinion Neurobiol 2:3-8.

Dolle P, Lufkin T, Kummlauf R, Mark M, Duboule D, Chambon P (1993) Local alterations of Krox-20 and Hox gene expression in the hindbrain suggest lack of rhombomeres 4 and 5 in homozygote null Hoxa-1 (Hox-1.6) mutant embryos. Proc Natl Acad Sci USA 90: 7666-7670.

Dorsky RI, Rapaport DH, Harris WA (1995) Xotch inhibits cell differentiation in the Xenopus retina. Neuron 14:487-496.

Echelard Y, Epstein DJ, St-Jacques B, Shen L, Mohler J, McMahon JA, McMahon AP (1993) Sonic hedgehog, a member of a family of putative signaling molecules, is implicated in the regulation of CNS polarity. Cell 75:1417-1430.

Eisen JS (1991) Determination of primary motoneuron identity in developing zebrafish embryos. Science 252:569-572.

Eisen JS (1994) Development of motoneuronal phenotype. Annu Rev Neurosci 17:1-30.

Ericson J, Thor S, Edlund T, Jessell TM, Yamada T (1992) Early stages of motor neuron differentiation revealed by expression of homeobox gene Islet-1. Science 256:1555-1560.

Figdor MC, Stern CD (1993) Segmental organization of embryonic diencephalon. Nature 363:630-634.

Finney M, Ruvkun G, Horvitz HR (1988) The C. elegans cell lineage and differentiation gene unc- 86 encodes a protein with a homeodomain and extended similarity to transcription factors. Cell 55:757769.

Fishell G (1995) Striatal precursors adopt cortical identities in response to local cues. Development 121:803-812.

Fishell G, Mason CA, Hatten ME (1993) Dispersion of neural progenitors within the germinal zones of the forebrain. Nature 362:636-638.

Frantz GD, Bohner AP, Akers RM, McConnell SK (1994) Regulation of the POU-domain gene SCIP during cerebral cortical development. J Neurosci 14:472-485.

Frantz GD, Weimann JM, Levin ME, McConnell SK (1994) Otx1 and Otx2 define layers and regions in developing cerebral cortex and cerebellum. J Neurosci 14:5725-5740.

Frantz GD, Kaznowski CE, McConnell SK (1995) Upper-layer cortical progenitor cells exhibit restricted developmental potential. Soc Neurusci Abstr 21:528.

Fraser S, Keynes R, Lumsden A (1990) Segmentation in the chick embryo hindbrain is defined by cell lineage restrictions. Nature 344 : $431-435$.

Galileo DS, Gray GE, Owens GC, Majors J, Sanes JR (1990) Neurons and glia arise from a common progenitor in chick optic tectum: demonstration with two retroviruses and cell type-specific antibodies. Proc Natl Acad Sci USA 87:458-462.

Ghosh A, Antonini A, McConnell SK, Shatz CJ (1990) Requirement for subplate neurons in the formation of thalamocortical connections. Nature 347:179-181.

Ghosh A, Shatz CJ (1993) A role for subplate neurons in the patterning of connections from thalamus to neocortex. Development 117:10311047.

Gillies K, Price DJ (1993) The fates of cells in the developing cerebral cortex of normal and methylazoxymethanol acetate-lesioned mice. Eur J Neurosci 5:73-84.

Götz M, Williams BP, Bolz J, Price J (1995) The specification of neuronal fate: a common precursor for neurotransmitter subtypes in the rat cerebral cortex in vitro. Eur J Neurosci 7:889-898.

Gray GE, Leber SM, Sanes JR (1990) Migratory patterns of clonally related cells in the developing nervous system. Experientia 46:929940.

Greenwald I (1989) Cell-cell interactions that specify certain cell fates in C. elegans development. 5:237-241.

Grove EA, Williams BP, Li DQ, Hajihosseini M, Friedrich A, Price J (1993) Multiple restricted lineages in the embryonic rat cerebral cortex. Development 117:553-561.

Gurdon JB (1988) A community effect in animal development. Nature $336: 772-774$
Guthrie S, Lumsden A (1991) Formation and regeneration of rhombomere boundaries in the developing chick hindbrain. Development 112:221-229.

Guthrie S, Lumsden A (1992) Motor neuron pathfinding following rhombomere reversals in the chick embryo hindbrain. Development 114:663-673.

Guthrie S, Prince V, Lumsden A (1993) Selective dispersal of avian rhombomere cells in orthotopic and heterotopic grafts. Development 118:527-538.

Harris WA, Holt CE (1990) Early events in the embryogenesis of the vertebrate visual system: cellular determination and pathfinding. Annu Rev Neurosci 13:155-169.

Hatta K (1992) Role of the floor plate in axonal patterning in the zebrafish CNS. Neuron 9:629-642.

Hatta K, Kimmel CB, Ho RK, Walker C (1991) The cyclops mutation blocks specification of the floor plate of the zebrafish central nervous system. Nature 350:339-341.

He X, Treacy MN, Simmons DM, Ingraham HA, Swanson LW, Rosenfeld MG (1989) Expression of a large family of POU-domain regulatory genes in mammalian brain development. Nature 340:35-42.

IIemond SG, Glover JC (1993) Clonal patterns of cell proliferation, migration, and dispersal in the brainstem of the chicken embryo. J Neurosci 13:1387-1402.

Herr W, Sturm RA, Clerc RG, Corcoran LM, Baltimore D, Sharp PA, Ingraham HA, Rosenfeld MG, Finney M, Ruvkun G, Horvitz HR (1988) The POU domain: a large conserved region in the mammalian pit-1, oct-1, oct-2 and Caenorhabditis elegans unc- 86 gene products. Genes Dev 2:1513-1516.

Hirano S, Fuse S, Sohal GS (1991) The effect of the floor plate on pattern and polarity in the developing central nervous system. Science 251:310-313.

Holt CE, Bertsch TW, Ellis HM, Harris WA (1988) Cellular determination in the Xenopus retina is independent of lineage and birthdate Neuron 1:15-26.

Ingraham HA, Chen R, Mangalam HJ, Elsholtz HP, Flynn SE, Lin CR, Simmons DR, Swanson L, Rosenfeld MG (1988) A tissue-specific transcription factor containing a homeodomain specifies a pituitary phenotype. Cell 55:519-529.

Katz LC (1991) Specificity in the development of vertical connections in cat striate cortex. Eur J Neurosci 3:1-9.

Keynes R, Krumlauf R (1994) Hox genes and regionalization of the nervous system. Annu Rev Neurosci 17:109-132.

Kim GJ, Shatz CJ, McConnell SK (1991) Morphology of pioneer and follower growth cones in the developing cerebral cortex. J Neurobiol 22:629-642.

Koester SE, O'Leary DD (1993) Connectional distinction between callosal and subcortically projecting cortical neurons is determined prior to axon extension. Dev Biol 160:1-14.

Krumlauf R (1994) Hox genes in vertebrate development. Cell 78:191201.

Krumlauf R, Marshall H, Studer M, Nonchev S, Sham MH, Lumsden A (1993) Hox homeobox genes and regionalisation of the nervous system. J Neurobiol 24:1328-1340.

Kuratani SC, Eichele G (1993) Rhombomere transplantation repatterns the segmental organization of cranial nerves and reveals cell-autonomous expression of a homeodomain protein. Development 117:105117.

Lance-Jones C, Landmesser L (1980) Motoneurone projection patterns in the chick hind limb following early partial reversals of the spinal cord. J Physiol (Lond) 302:581-602.

Leber SM, Breedlove SM, Sanes JR (1990) Lineage, arrangement and death of clonally related motoneurons in chick spinal cord. $\mathbf{J}$ Neurosci 10:2451-2462.

Levitt P, Cooper ML, Rakic P (1981) Coexistence of neuronal and glial precursor cells in the cerebral ventricular zone of the fetal monkey: an ultrastructural immunoperoxidase analysis. J Neurosci 1:27-39.

Li S, Crenshaw EBI, Rawson EJ, Simmons DM, Swanson LW, Rosenfeld MG (1990) Dwarf locus mutants lacking three pituitary cell types result from mutations in the POU-domain gene pit-1. Nature 347:528-533.

Lumsden A (1990) The cellular basis of segmentation in the developing hindbrain. Trends Neurosci 13:329-335.

Lumsden A, Clarke JD, Keynes R, Fraser S (1994) Early phenotypic choices by neuronal precursors, revealed by clonal analysis of the chick embryo hindbrain. Development 120:1581-1589. 
Luskin MB, Pearlman AL, Sanes JR (1988) Cell lineage in the cerebral cortex of the mouse studied in vivo and in vitro with a recombinant retrovirus. Neuron 1:635-647.

Mark M, Lufkin T, Vonesch JL, Ruberte E, Olivo JC, Dolle P, Gorry P, Lumsden A, Chambon P (1993) Two rhombomeres are altered in Hoxa-1 mutant mice. Development 119:319-338.

Marshall H, Nonchev S, Sham MH, Muchamore I, Lumsden A, Krumlauf R (1992) Retinoic acid alters hindbrain Hox code and induces transformation of rhombomeres $2 / 3$ into a $4 / 5$ identity. Nature 360 : $737-741$.

McConnell SK (1988a) Development and decision-making in the mammalian cerebral cortex. Brain Res Rev 13:1-23

McConnell SK (1988b) Fates of visual cortical neurons in the ferret after isochronic and heterochronic transplantation. J Neurosci 8:945974.

McConnell SK (1991) The generation of neuronal diversity in the central nervous system. Annu Rev Neurosci 14:269-300.

McConnell SK (1992) The genesis of neuronal diversity during development of cerebral cortex. Semin Neurosci 4:347-356.

McConnell SK, Kaznowski CE (1991) Cell cycle dependence of laminar determination in developing cerebral cortex. Science 254:282285.

McConnell SK, Ghosh A, Shatz C.I (1994) Subplate pioneers and the formation of descending connections from cerebral cortex. J Neurosci 14:1892-1907

Mione MC, Dancvic C, Boardman P, Harris B, Parnavelas JG (1994) Lineage analysis reveals neurotransmitter (GABA or glutamate) but not calcium-binding protein homogeneity in clonally related cortical neurons. J Neurosci 14:107--123.

Monuki ES, Weinmaster G, Kuhn R, Lemke G (1989) SCIP: a glial POU domain gene regulated by cyclic AMP. Neuron 3:783-793.

Nye JS, Kopan R, Axel R (1994) An activated Notch suppresses neurogenesis and myogenesis but not gliogenesis in mammalian cells. Development 120:2421-2430.

O'Leary DDM (1989) Do cortical areas emerge from a protocortex? Trends Neurosci 12:400-406.

O'Leary DDM, Stanfield BB (1989) Selective elimination of axous extended by developing cortical neurons is dependent on regional locale: experiments utilizing fetal cortical transplants. J Neurosci 9:2230-2246.

O'Leary DD, Schlaggar BL, Tuttle R (1994) Specification of neocortical areas and thalamocortical connections. Annu Rev Neurosci 17 : $419-439$.

O'Rourke NA, Dailey ME, Smith SJ, McConnell SK (1992) Diverse migratory pathways in the developing cerebral cortex. Science 258: 299-302.

O'Rourke NA, Sullivan DP, Kaznowski CE, Jacobs AA, McConnell SK (1995) Tangential migration of neurons in the developing cerebral cortex. Development 121:2165-2176.

Parnavelas JG, Barfield JA, Franke E, Luskin MB (1991) Separate progenitor cells give rise to pyramidal and nonpyramidal neurons in the rat telencephalon. Cereb Cortex 1:463-468.

Pfaffle RW, DiMattia GE, Parks JS, Brown MR, Wit JM, Jansen M, Van der Nat $H$, Van den Brande JL, Rosenfeld MG, Ingraham HA (1992) Mutation of the POU-specific domain of Pit-1 and hypopituitarism without pituitary hypoplasia. Science 257:1118-1121.

Placzek M, Jessell TM, Dodd J (1993) Induction of floor plate differentiation by contact-dependent, homeogenetic signals. Development 117:205-218.

Placzek M, Yamada T, Tessier-Lavigne M, Jessell T, Dodd J (1991) Control of dorsoventral pattern in vertebrate neural development: induction and polarizing properties of the floor plate. Dev Suppl 2:105122.

Porteus MH, Bulfone A, Ciaranello RD, Rubenstein JL (1991) Isolation and characterization of a novel cDNA clone encoding a homeodomain that is developmentally regulated in the ventral forebrain. Neuron 7:221-229.

Price J, Thurlow L (1988) Cell lineage in the rat cerebral cortex: a study using retroviral-mediated gene transfer. Development 104:473482 .

Price J, Williams B, Grove E (1991) Cell lineage in the cerebral cortex. Dev Suppl 2:23-28.

Price M, Lemaistre M, Pischetola M, DiLauro R, Duboule D (1991) A mouse gene related to Distal-less shows a retricted expression in the developing forebrain. Nature 351:748-751.

Price M, Lazzaro D, Pohl T, Mattei MG, Ruther U, Olivo JC, Duboule D, DiLauro R (1992) Regional expression of the homeobox gene Nkx-2.2 in the developing mammalian forebrain. Neuron 8:241-255.

Puelles L, Rubenstein JL (1993) Expression patterns of homeobox and other putative regulatory genes in the embryonic mouse forebrain suggest a neuromeric organization. Trends Neurosci 16:472-479.

Rakic P (1974) Neurons in the rhesus monkey visual cortex: systematic relationship between time of origin and eventual disposition. Science 183:425-427.

Reh TA, Tully T (1986) Regulation of tyrosine-hydroxylase-containing amacrine cell number in the larval frog retina. Dev Biol 114:463469.

Reid CB, Liang I, Walsh C (1995) Systematic widespread clonal organization in cerebral cortex. Neuron 15:299-310.

Roelink H, Augsburger A, Heemskerk J, Korzh V, Norlin S, Ruiz i Altaba A, Tanabe Y, Placzek M, Edlund T, Jessell TM, Dodd J (1994) Floor plate and motor neuron induction by vhh-1, a vertebrate homolog of hedgehog expressed by the notochord. Cell 76:761-775.

Rosenfeld MG (1991) POU-domain transcription factors: pou-cr-ful dcvelopmental regulators. Genes Dev 5:897-907.

Schlagger BL, O'Leary DDM (1991) Potential of visual cortex to develop an array of functional units unique to somatosensory cortex. Science 252:1556-1560.

Schöler HR (1991) Octamania: the POU factors in murine development. Trends Genet 7:323-329.

Selleck MAJ, Bronner-Fraser M (1995) Origins of the avian neural crest: the role of neural plate-epidermal interactions. Development 121:525-538.

Shatz C (1992) Dividing up the neocortex. Science 258:237-238.

Simeone A, Acampora D, Gulisano M, Stornaiuolo A, Boncinelli E (1992a) Nested expression domains of four homeobox genes in developing rostral brain. Nature 358:687-690.

Simeone A. Gulisano M, Acampora D, Stornaiuolo A, Rambaldi M, Boncinelli E (1992b) Two vertebrate homeobox genes related to the Drosophila empty spiracles gene are expressed in the embryonic cerebral cortex. EMBO J 11:2541-2550.

Stanfield BB, O'Leary DDM (1985) Fetal occipital cortical neurones transplanted to the rostral cortex can extend and maintain a pyramidal tract axon. Nature 313:135-137.

Stent GS (1985) The role of cell lineage in development. Philos Trans R Soc Lond [Biol] 312:3-19.

Sulston PW, Horvitz HR (1977) Postembryonic cell lineages of the nematode, Caenorhabditis elegans. Dev Biol 56:110-156.

Suzuki N, Rohdewohld H, Neuman T, Gruss P, Schöler HR (1990) Oct6: a POU transcription factor expressed in embryonal stem cells and in the developing brain. EMBO J 9:3723-3732.

Tsuchida T, Ensini M, Morton SB, Baldassare M, Edlund T, Jessell TM, Pfaft SL (1994) Topographic organization of embryonic motor neurons defined by expression of LIM homeobox genes. Cell 79:957970.

Turner DL, Cepko CL (1987) Cell lineage in the rat retina: A common progenitor for neurons and glia persists late in development. Nature 328:131-136.

Walsh C, Cepko CL (1988) Clonally related cortical cells show several migration patterns. Science 241:1342-1345.

Walsh C, Cepko CI. (1992) Widespread dispersion of neuronal clones across functional regions of the cerebral cortex. Science 255:434440 .

Weinmaster G, Roberts VJ, Lemke G (1991) A homolog of Drosophila Notch expressed during mammalian development. Development 113: 199-205.

Wetts R, Fraser SE (1988) Multipotent precursors can give rise to all major cell types of the frog retina. Science 239:1142-1145.

Wilkinson DG, Krumlauf R (1990) Molecular approaches to the segmentation of the hindbrain. Trends Neurosci 13:335-339.

Yamada T, Placzek M, Tanaka H, Dodd J, Jessell TM (1991) Control of cell pattern in the developing nervous system: polarizing activity of the floor plate and notochord. Cell 64:635-64\%

Yamada T, Pfaff SL, Edlund T, Jessell TM (1993) Control of cell pattern in the neural tube: motor neuron induction by diffusible factors from notochord and floor plate. Cell 73:673-686.

Yamamoto N, Yamada K, Kurotani T, Toyama K (1992) Laminar specificity of extrinsic cortical connections studied in coculture preparations. Neuron 9:217-228. 